\title{
Correcting estimates of net primary production: Are we overestimating plant production in rangelands?
}

\author{
MARIO E. BIONDINI, WILLIAM K. LAUENROTH, AND OSVALDO E. SALA
}

\begin{abstract}
This paper addresses the issue of the effect of random errors in field estimates of net primary production (NPP). This is a critical subject in range management because field estimates of plant production are regularly used to determine stocking rates, range condition, and animal consumption. What we show in this paper is that random errors associated with field estimates of NPP can result in a positive bias and thus an overestimation of NPP. Depending on the case, this overestimation has been reported as high as $700 \%$. We present examples with overestimations in the $200 \%$ to $400 \%$ range. The overestimation in NPP increases with increases in biomass variances, frequency of sampling, and number of taxonomic (species) and tissue (live, dead, etc) components sampled. We (1) outline in nonmathematical terms the reasons behind overestimation in NPP and the analytical solutions designed to correct them; and (2) present applications of the analytical solution for adjustments to concrete cases. The adjustments for overestimation outlined in this paper do not guarantee an accurate estimate of NPP but eliminate an unneeded source of error. A computer program (for IBM ${ }^{\mathrm{TM}}$ compatible) designed to implement the necessary adjustments is available from the authors free of charge (send a blank diskette).
\end{abstract}

An article published by Singh et al. (1984) initiated a controversy in plant ecology about the accuracy of field estimates of net primary production (NPP) based upon a time series of biomass. This controversy is of particular relevance to range science because field estimates of plant production are regularly used to determine range condition, stocking rates, and animal consumption. Accurate estimates of primary production are also very important for scientists and natural resource managers concerned with a wide variety of issues such as global carbon (C) budgets (Schneider 1989), soil organic matter, and herbivory.

Singh et al. (1984) used simulation models to show that most of the techniques used to estimate NPP (for a review see Singh et al. 1975) can overestimate net root production by as much as $700 \%$. Similar results were reported for aboveground production by Lauenroth et al. (1986a). Both results contradicted previous assumptions that field estimates of NPP always underestimate NPP because biomass peaks may be missed and because of the simultaneous nature of production and decomposition. Singh et al. (1984) related NPP overestimation to the random errors associated with biomass estimates. They suggested that random errors can generate artificial peaks and troughs (false maxima and minima) in a time of series of biomass estimates which may lead to large overestimation of NPP. Vogt et al. (1986), however, challenged the conclusions of Singh et al. (1984) both on methodological grounds and by suggesting that they may be related to the peculiarity of the grasslands under study and thus not generally applicable. Subsequently, Lauenroth et al. (1986b) answered the methodological

\footnotetext{
Authors are associate professor, Department of Animal and Range Sciences, North Dakota State University, Fargo 58105; professor, Department of Range Science, Colorado State University, Fort Collins 80523 ; associate professor, Departamento de Ecologia, Facultad the Agronomia, Universidad de Buenos Aires, Av. San Martin 4453, Argentina.

Support for this study was provided by the shortgrass steppe Long-Term Ecological Research program (NSF grant BSR-8114822), the North Dakota Experiment Station and Consejo Nacional the Investigaciones Cientificas y Tecnicas of Argentina (INT $151 / 87$, PID 427/89). This is a North Dakota Experiment Station Publication Number 1898.

Manuscript accepted 23 July 1990.
}

questions raised by Vogt et al. (1986) but left open the problem of generating a statistical theory to explain why NPP overestimation may occur, and developing the analytical tools needed to correct them. Sala et al. (1988) provided the answer for both.

The objectives of this paper are: (1) to outline in nonmathematical terms the reasons behind overestimation in NPP and the analytical solution designed to correct it; and (2) present applications of the analytical solution for adjustments developed by Sala et al. (1988) to specific cases.

\section{Random Errors and NPP Overestimation}

We will use an example to explain the connection between random errors and overestimation of NPP (Fig. 1). Let's assume that the mean biomass of a pasture is $110 \mathrm{~g} \cdot \mathrm{m}^{-2}$ at time 1 (B1) and $120 \mathrm{~g} \cdot \mathrm{m}^{-2}$ at time 2 (B2), and furthermore, let's assume that both means are normally distributed (Fig. la and $1 \mathrm{~b}$ ). That implies that in the time 1 - time 2 interval there has been a mean increase in biomass (B2-B1) of $10 \mathrm{~g} \cdot \mathrm{m}^{-2}$ which we would consider as the NPP for the period. Under field conditions, of course, we do not know the actual mean and standard deviation (sd) of the biomass in the pasture in question so we estimate it by sampling. For instance, 30 random samples from Figure 1a and $1 \mathrm{~b}$, respectively, resulted in estimated mean and sd of $109.8 \mathrm{~g} \cdot \mathrm{m}^{-2}, 8.1$ for B1 and $118 \mathrm{~g} \cdot \mathrm{m}^{-2}, 18.8$ for B2. A t-test for a case of unequal variance (Snedecor and Cochran 1967) gives a $t=2.24$ with a $p=0.028(d f=39.5)$ confirming that there is in fact an increase in mean biomass in that period. Now, the underlying distribution of B2-B1, which represents the differences in biomass between time 1 and time 2 , is also normally distributed with a mean of $10 \mathrm{~g} \cdot \mathrm{m}^{-2}$ and sd of 22.4 (Fig. 1c). Sala et al. (1988) showed, however, that the underlying distribution of NPP estimates from all commonly used techniques is not normally distributed, but rather a combination of 2 distributions: a discrete distribution with mass at 0 and a truncated normal distribution (Fig. 1d, and Appendix). The explanation can be intuitively captured by the following argument. Even though the mean of B2-B1 is positive, there is a probability $(0.33$ in this example) that when sampling from Figure 1c one would get a negative value by chance alone. NPP is not the difference B2-B1, but only the positive values of this difference. As a result, every time a negative value for B2-B 1 is obtained, NPP is assigned a value of 0 . That represents the discrete portion of the NPP distribution that has mass at $\mathbf{0}$ (Fig. 1d). When the difference B2-B1 is positive, we assign NPP that value, but the distribution of positive values is a truncated normal distribution rather than a normal one. Although the mean B2-B1 (actual NPP) is $10 . \mathrm{g} \cdot \mathrm{m}^{-2}$, the mean derived from the distribution of NPP estimates (we call it the calculated NPP) is $14.6 \mathrm{~g} \cdot \mathrm{m}^{-2}$. The difference between the actual and calculated values represents the overestimation observed by Singh et al. (1984).

Sala et al. (1988) developed equations that relate the calculated NPP to the actual NPP, estimated the size of the overestimation, and developed algorithms needed to adjust the calculated NPP values to correct for overestimation (Appendix). Sala et al. (1988) also developed the theoretical proofs for results observed by Singh et al. (1984): (1) overestimation increases as the variance of the estimated biomass increases; (2) the closer (though still significantly different) the mean biomasses are between 2 sampling peri- 

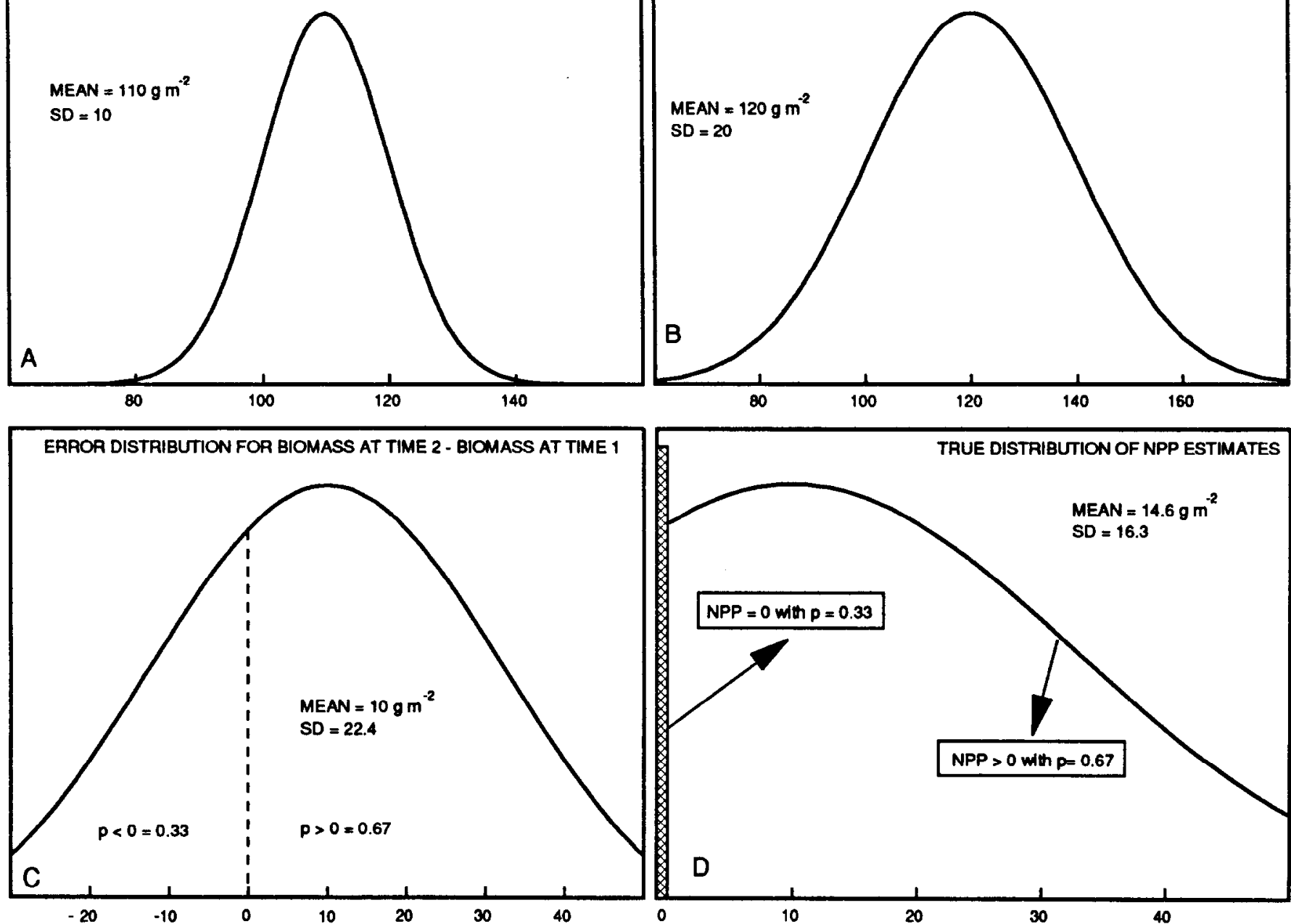

Fig. 1. (a) and (b) represent the distribution of biomass estimation errors associated with samples taken at time 1 and time 2;(c) distribution of difference of biomass between time 2 and time 1; (d) actual distribution of NPP estimates. For details see Appendix.

ods the higher the overestimation (as a percentage); and (3) increasing the frequency of sampling results in increasingly greater overestimation.

\section{Example 1}

In the following example we reanalyzed a subset of the Singh et al. (1984) NPP estimates of root biomass to show how the adjustment method is implemented and to compare the adjusted results with the published data. The data consist of the total root biomass (live + dead) generated by a simulation model for a 4-year period. Samples for a given date were generated by assuming that root biomass per sample period was normally distributed with mean equal to model estimates and a coefficient of variation of 0.32 (derived from Lauenroth and Whitman 1977). Ten samples were taken at 15-day intervals from 15 May through 1 September, and at 30-day intervals from 1 September and through 1 November (Table 1). NPP was estimated as the sum of the significantly different $(\mathrm{p}<0.05)$ increments in root biomass. The actual NPP $\left(566 \mathrm{~g} \cdot \mathrm{m}^{-2}\right)$ in this case is a known value because it was generated from a simulation model.

According to theory (Singh et al. 1975), the use of a time series of total root biomass with statistical constraints should lead to a substantial underestimation of root NPP because of missed biomass peaks, small biomass increments in relationship to standing crop, rapid biomass turnover, and translocation of $\mathrm{C}$ between shoots and roots (Wiegert and Evans 1964). Estimates of root production from harvest data, however, often result in overestimation. Results from the analysis of the Singh et al. (1984) data show that root NPP is overestimated by an average of $150 \%$ (Table 1). When we apply the adjustments developed by Sala et al. (1988), the estimates of NPP behave as expected by theory, that is they underestimate actual NPP by an average of $33 \%$. This is the desired behavior because underestimation in this case results from the limitations of the sampling method used rather than from a statistical artifact (the overestimation case) and can be reduced, if adjustments for overestimation are used, by more refined and intensive sampling protocols such as separating live and dead biomass, estimating decomposition and herbivory, and increasing the number and frequency of samples.

We use the case of Year 1 in Table 1 to illustrate how the adjustments are implemented. The procedure is as follows:

Step 1. Select a method to estimate NPP. In this example NPP is estimated as the summation of the significant $(p<0.05)$ increments in total root biomass (live + dead) (Singh et al. 1984). As a consequence, adjustments will be calculated only in the cases where 
Table 1. Reanalysis of the Singh et al (1984) NPP estimates of root biomass. The data for each sampling date represent mean and standard deviations for total (live + dead) root biomass in $\mathrm{g} \mathrm{m}^{-2}$. Samples for a given date were generated by assuming that root biomass was normally distributed with mean equal to the model estimates and a coeficient of variation of 0.32 . Ten samples were taken per date. Four years are simulated. Root NPP was estimated as the summation of the significant $(p<0.05$ ) increments in root biomass (Singh et al. 1975). The actual value of root NPP (calculated from model flows) was $566 \mathrm{~g} \mathrm{~m}^{-2}$ year $^{-1}$.

\begin{tabular}{|c|c|c|c|c|c|c|c|c|}
\hline & \multicolumn{2}{|c|}{ Year 1} & \multicolumn{2}{|c|}{$\begin{array}{c}\text { Total Root Biomass }\left(\mathrm{g} \mathrm{m}^{-2}\right) \\
\text { Year } 2\end{array}$} & \multicolumn{2}{|c|}{ Year 3} & \multicolumn{2}{|c|}{ Year 4} \\
\hline & Mean & Sd & Mean & Sd & Mean & Sd & Mean & Sd \\
\hline $\begin{array}{l}\text { May } 15 \\
\text { June } 1 \\
\text { June } 15 \\
\text { July } 1 \\
\text { July } 15 \\
\text { Aug. } 1 \\
\text { Aug. } 15 \\
\text { Sep. } 1 \\
\text { Oct. } 1 \\
\text { Nov. } 1\end{array}$ & $\begin{array}{l}3080 \\
3197 \\
2944 \\
3468 \\
3210 \\
2777 \\
3440 \\
3219 \\
3134 \\
3339\end{array}$ & $\begin{array}{r}492 \\
875 \\
419 \\
909 \\
894 \\
749 \\
361 \\
980 \\
1154 \\
706\end{array}$ & $\begin{array}{l}3180 \\
3298 \\
2800 \\
3216 \\
3040 \\
3926 \\
3404 \\
3563 \\
2835 \\
3787\end{array}$ & $\begin{array}{r}875 \\
868 \\
1003 \\
809 \\
1272 \\
978 \\
997 \\
889 \\
812 \\
838\end{array}$ & $\begin{array}{l}2665 \\
3120 \\
2644 \\
2812 \\
3348 \\
2929 \\
3165 \\
3495 \\
2741 \\
3748\end{array}$ & $\begin{array}{r}779 \\
1074 \\
808 \\
700 \\
729 \\
1083 \\
882 \\
1385 \\
1093 \\
983\end{array}$ & $\begin{array}{l}3330 \\
3181 \\
3049 \\
2633 \\
3417 \\
2895 \\
3391 \\
3535 \\
3252 \\
3406\end{array}$ & $\begin{array}{r}996 \\
879 \\
587 \\
785 \\
834 \\
1158 \\
859 \\
1133 \\
1221 \\
814\end{array}$ \\
\hline $\begin{array}{l}\text { Actual NPP } \\
\text { Estimated NPP } \\
\text { Adjusted NPP }\end{array}$ & $\begin{array}{l}566 \\
663 \\
353\end{array}$ & & $\begin{array}{l}566 \\
952 \\
528\end{array}$ & & $\begin{array}{r}566 \\
1007 \\
360\end{array}$ & . & $\begin{array}{l}566 \\
784 \\
278\end{array}$ & \\
\hline
\end{tabular}

Four Year Average

\begin{tabular}{ll} 
Actual NPP & 566 \\
Estimated NPP & 851 \\
Adjusted NPP & 380 \\
\hline
\end{tabular}

there are significant increases in total root biomass between consecutive dates.

Step 2. Identify all the significant $(p<0.05)$ increases in biomass between 2 consecutive dates. In this example the only significant increase takes place between 1 August and 15 August (3440 - 2777 $=663 \mathrm{~g} \cdot \mathrm{m}^{-2}$ ). This represents the nonadjusted value.

Step 3. For all the cases where there is a significant increase in biomass, calculate the probability of finding by chance alone a decrease in biomass between the given dates (the area in the left hand side of Fig. Ic). To do that, we first calculate the normal deviate $\mathrm{z}=-\mathrm{D} / \mathrm{SD}$ where $\mathrm{D}$ is the difference in biomass between the 2 consecutive dates in question (B2-B1) and $\mathrm{SD}=$ standard deviation of $B 2-B 1=(\text { Variance of } B 1+\text { Variance of } B 2)^{1 / 2}$. In our case $D=$ $3440-2777=663, \mathrm{SD}=\left[(749)^{2}+(361)^{2}\right]^{1 / 2}=831$ and $\mathrm{z}=-663 / 831=$ -0.8 . Second, calculate the value $q=P(Z<-0.8)$ using a table for the cumulative standard normal distribution. To do that we first look at the table value for $\mathrm{z}=0.8$, using for instance Table $\mathrm{A} 3$ (page 548) of Snedecor and Cochran (1967), and then calculate $q=0.5-z$. In this case $\mathrm{z}=0.2881$ and $\mathrm{q}=0.5-0.2881=0.21$.

Step 4. To eliminate the effect of overestimation, i.e., calculate the adjusted mean and standard deviations, we need to solve equations (1) and (2), shown in the Appendix, where $E(N P P)=B 2$ - B1, Var $(N P P)=(S D)^{2}$ and $p=1-q$. In our particular example $E(N P P)=663, \operatorname{Var}(N P P)=(831)^{2}=691,322, p=1-0.21=0.79$. The values we need to solve for are $\mu$, which represents the adjusted (for overestimation) mean difference in total biomass between 1 August and 15 August and $\sigma$, which represents the corresponding adjusted standard deviation. Replacing E(NPP), $\operatorname{Var}(\mathrm{NPP})$ and $p$ in equations (1) and (2) of the Appendix with the values shown above led to the following system of equations to be solved:

$$
\begin{aligned}
& 663=0.79 \mu+\sigma(0.4)(2.72)^{-0.5(\mu / \sigma)^{2}} \\
& 691,322=0.79 \mu^{2}(0.21)+0.79 \sigma^{2}+\mu \sigma(0.4)(2.72)^{-0.5(\mu / \sigma)^{2}}(-0.58)- \\
& \sigma^{2}(0.16)(2.72)^{-(\mu / \sigma)^{2}}
\end{aligned}
$$

The equations are solved for $\mu$ and $\sigma$ using an approximation algorithm developed by Sala et al. (1988). The process is iterative in nature and stops when the right and left side of the equations differ by less than $5 \%$. In this case $\mu=353$ and $\sigma=1055$ are the solutions. A computer program has been developed by the authors for this purpose and is available free of charge. The program tests for significant differences between means and solves for $\mu$ and $\sigma$. The only inputs required are mean biomass, standard deviation, and number of observations for each time period.

Step 5. Once all the significant biomass differences between consecutive dates are adjusted, NPP is calculated according to the selected method. In this case there was only 1 significant increment in biomass between consecutive dates therefore adjusted NPP $=\mu=$ 353 rather than $663 \mathrm{~g}$.

Once adjustments for overestimation are performed, more sophisticated methods for field estimations of NPP that involve frequent sampling, separation of live and dead material, estimation of decomposition rates, and estimations of $\mathrm{C}$ translocation (Sala et al. 1981) can be safely used to obtain more accurate estimates of NPP without the risk of incurring the large overestimation shown by Singh et (1984).

\section{Example 2}

In this example, we show the estimation of aboveground NPP with a method that accounts for changes in live biomass of individual species, standing dead biomass and litter. The data for the example comes from Sala et al. (1981). NPP is calculated in 2 ways: (1) using a time series of live biomass only; and (2) using a time series of live biomass plus changes in standing dead and litter to account for senescence and decay processes.

Method 1 involves the summation of significant $(p<0.05)$ increments in live biomass between consecutive dates for all species (Table 2). For example, Bothriochloa laguroides has significant increases in biomass in the December (1974) to January (1975), January to April and October to December (1975) intervals. The non adjusted biomass increments are $7.5,6.7$, and $13.2 \mathrm{~g} . \mathrm{m}^{-2}$, respectively. To adjust, we follow the same 4 steps of example 1 and apply it to each pair of consecutive dates. The adjusted biomass increments are $5.8,0$ (the actual value is -2.7 but the protocols for this method involve only biomas increments) and $3 \mathrm{~g} \cdot \mathrm{m}^{-2}$. The same procedure is repeated for each species, and the nonadjusted and adjusted for (overestimation) NPP estimates are calculated by summing all the increments (Table 2).

Method 2 involves corrections to the NPP values of Method 1 by 
Table 2. Reanalysis of Sala et al. (1981) NPP estimates. Data is given in g. $\mathrm{m}^{-2}$. NPP is calculated 2 ways: (1) sum of significant (p<0.05) positive increments of live biomass; (2) as in 1 plus correction factors for senescence and decay processes using a time series of standing dead and litter. Senescence corrections were calculated as the increments in standing dead not justified by the summation of decreases in the live biomass of individual species. The decay correction factor was calculated as the increases in litter not justified by decreases in standing crop. For details on the calculations see text and Sala et al. (1981).

\begin{tabular}{|c|c|c|c|c|c|c|c|c|c|c|c|c|c|c|c|c|c|c|}
\hline \multirow[b]{2}{*}{ Species } & \multicolumn{3}{|c|}{ December 1974} & \multicolumn{3}{|c|}{ January } & \multicolumn{3}{|c|}{ April } & \multicolumn{3}{|c|}{ August } & \multicolumn{3}{|c|}{ October } & \multicolumn{3}{|c|}{ December 1975} \\
\hline & $\begin{array}{l}\text { Bio- } \\
\text { mass }\end{array}$ & Sd & $\mathbf{n}$ & $\begin{array}{l}\text { Bio- } \\
\text { mass }\end{array}$ & Sd & $\mathbf{n}$ & $\begin{array}{l}\text { Bio- } \\
\text { mass }\end{array}$ & Sd & $\mathbf{n}$ & $\begin{array}{l}\text { Bio- } \\
\text { mass }\end{array}$ & Sd & $\mathbf{n}$ & $\begin{array}{l}\text { Bio- } \\
\text { mass }\end{array}$ & Sd & $\mathbf{n}$ & $\begin{array}{l}\text { Bio- } \\
\text { mass }\end{array}$ & Sd & $\mathbf{n}$ \\
\hline $\begin{array}{l}\text { Bothriochloa laguroides } \\
\text { Briza subaristata }\end{array}$ & $\begin{array}{r}1.8 \\
38.9\end{array}$ & $\begin{array}{r}1.6 \\
34.1\end{array}$ & $\begin{array}{l}33 \\
33\end{array}$ & $\begin{array}{r}9.3 \\
32.7\end{array}$ & $\begin{array}{r}6.8 \\
27.4\end{array}$ & $\begin{array}{l}40 \\
40\end{array}$ & $\begin{array}{l}16.0 \\
18.3\end{array}$ & & $\begin{array}{l}40 \\
40\end{array}$ & $\begin{array}{r}2.4 \\
39.2\end{array}$ & $\begin{array}{r}2.3 \\
24.4\end{array}$ & $\begin{array}{l}40 \\
40\end{array}$ & $\begin{array}{r}1.2 \\
65.5\end{array}$ & $\begin{array}{r}1.0 \\
39.5\end{array}$ & $\begin{array}{l}40 \\
40\end{array}$ & $\begin{array}{l}14.4 \\
51.2\end{array}$ & $\begin{array}{l}21.2 \\
29.8\end{array}$ & $\begin{array}{l}45 \\
45\end{array}$ \\
\hline $\begin{array}{l}\text { Danthonia } \\
\text { montevidensis }\end{array}$ & 24.4 & 20.0 & 33 & 16.2 & 11.0 & 40 & 21.8 & 15.5 & 40 & 26.3 & & 40 & 48.9 & 23.1 & 40 & 33.5 & 15.9 & 45 \\
\hline Distichlis sp. & 15.7 & 14.9 & 33 & 27.5 & 20.4 & 40 & 19.1 & 4.4 & 40 & 6.9 & 4.7 & 40 & 5.8 & 4.5 & 40 & 16.0 & 15.7 & 45 \\
\hline Lolium & 16.7 & 20.0 & 33 & 0.1 & 0.9 & & 0 & 0 & & & 2.3 & & & & & 0 & 0 & 45 \\
\hline Melica b & 3.7 & 13.6 & 33 & 2.0 & 5.5 & 40 & 0.5 & 2.4 & 4 & 1.3 & 3.3 & 40 & 1.0 & 3.8 & 40 & 1.8 & 7.2 & 45 \\
\hline & 0 & 0 & 33 & 2.4 & 12.3 & & 6.5 & 40.3 & & 0.7 & 3.1 & 40 & 0.7 & 2.4 & & & 3.4 & 45 \\
\hline & 1.5 & 1.7 & 33 & 1.2 & 1.9 & 40 & 1.1 & 1.6 & & 0.1 & 0.3 & 40 & & & & & 6 & 45 \\
\hline & 1.9 & 3.9 & 33 & 2.9 & 2.4 & 40 & 3.3 & 3.0 & & 2.5 & 2.0 & 40 & .2 & & & .8 & 2.8 & 45 \\
\hline is & 4.6 & 9.9 & 33 & 19.2 & 32.7 & 40 & 11.0 & 24.1 & & 13.7 & 25.9 & & 8.5 & 25 & & 12.6 & 29.9 & 45 \\
\hline & 31.0 & 25.4 & 33 & 17.4 & 16 & 40 & 18.0 & 113.0 & 4 & 19.4 & 151.3 & 4 & 22.5 & 21 & 0 & 33.0 & 23.5 & 45 \\
\hline id & & 18.3 & 33 & 15 & 15.0 & & 67 & 107.9 & & 20.4 & 24.7 & & 34.2 & 36 & & & 25.8 & 45 \\
\hline & 21.4 & 10.4 & 33 & 30.1 & 18.4 & 4 & 24.4 & 15 & 4 & 16.2 & & & 13.2 & & & 17.4 & 9.2 & 45 \\
\hline$A m$ & 0 & 0 & 33 & 8.3 & 6.4 & 4 & 14.6 & 12. & 4 & 2.2 & 1.5 & & 1.2 & & & 5.3 & 5.6 & 45 \\
\hline & 0.2 & 0.8 & 33 & 0 & 0 & 4 & 0. & 0.4 & 40 & 0 & 0 & & 0 & 0 & & 0 & 0 & 45 \\
\hline & 0 & & 3 & 0 & 0 & 4 & & & & 0 & 0 & & 0 & & & 0 & 0 & 45 \\
\hline $\begin{array}{l}\text { Stenotaphrum } \\
\text { secundatum }\end{array}$ & 0 & 0 & 33 & 0 & 0 & 40 & 0.5 & 2.0 & 40 & 0 & 0 & 40 & 0 & & 40 & 0 & 0 & 45 \\
\hline oides & 0 & 0 & 33 & 0 & 0 & 40 & 0.7 & 1.6 & & 0 & 0 & & 0 & & & 0 & 0 & 45 \\
\hline & 0 & 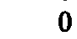 & & 0 & 0 & & & & & 0 & & & & & & 0 & & \\
\hline Panict & 0 & 0 & 33 & 0.4 & 1.2 & 4 & 1 & 7.2 & 4 & 0 & 0 & & 0 & 0 & & 0 & 0 & 45 \\
\hline $\begin{array}{l}\text { Piptochaetium } \\
\text { montevidense }\end{array}$ & 0 & 0 & 33 & 0 & 0 & 40 & 0.1 & 0.6 & 40 & 0 & 0 & 40 & 0 & 0 & 40 & 1.4 & 6.3 & 45 \\
\hline & 0 & 0 & & 0 & 0 & & & 1.7 & 4 & 0 & 0 & & 0 & 0 & & 0.1 & 0.9 & 45 \\
\hline & 0 & 0 & 33 & 0 & 0 & & & & & 0 & 0 & & 0 & 0 & & 0 & 0 & 45 \\
\hline & 0 & 0 & 33 & 0 & 0 & 4 & & 0.1 & 4 & 0 & 0 & & 0 & 0 & & 0 & 0 & 45 \\
\hline & 0 & 0 & 3 & 0 & 0 & & 0 & 0 & & 0.1 & 0.2 & & 0 & 0 & & 0 & 0 & 45 \\
\hline & 0 & 0 & 3 & 0 & 0 & 4 & . & 0 & 4 & & 0.4 & & 0 & 0 & & 0 & 0 & 45 \\
\hline moena & 0 & 0 & 33 & 0 & 0 & 4 & 0 & 0 & 4 & 0.1 & .2 & & 0.2 & 0.1 & & 0 & 0 & 45 \\
\hline & 0 & 0 & 33 & 0 & 0 & 4 & 0 & 0 & 4 & 0.7 & 0.7 & & & 0.1 & & 0 & 0 & 45 \\
\hline lugens & & 0 & 33 & 0 & 0 & & 0 & 0 & & 0 & 0 & & & & & 0 & 0 & 45 \\
\hline & 18.3 & 12.3 & 33 & 7.8 & 6.4 & & 7.0 & 5.9 & & 4.0 & 5.2 & & & & & 3.7 & 3.7 & 45 \\
\hline & 1.9 & 2.1 & 33 & 4.0 & 3.3 & 4 & 6.4 & 9.5 & 4 & 1.5 & 1.7 & 40 & 1.2 & & & 4 & 4.7 & 45 \\
\hline & 276.8 & 128.5 & 33 & & 111.9 & 4 & & 152.4 & 4 & 430.8 & 132.8 & 40 & & 124 & 40 & & 173.1 & 45 \\
\hline Litter & 137.6 & 54.4 & 33 & 137.6 & 54.4 & 40 & 125.6 & 65.8 & 40 & 81.3 & 50.7 & 40 & 129.9 & 53.3 & 40 & 128.5 & 53.6 & 45 \\
\hline
\end{tabular}

NPP with method 1 Adjusted NPP with method 1

NPP with method 2 Adjusted NPP with method 2

188.1

taking into account senescence and decay (Sala et al. 1981). The senescence correction is calculated as the increases in standing dead that are not justified by the sum of the decreases in the live biomass of individual species. For example, if between time 1 and time 2 a set of species shows a decrease in live biomass of $10 \mathrm{~g} . \mathrm{m}^{-2}$, but the increase for the same period in standing dead biomass is 15 g. $\mathrm{m}^{-2}$, the difference of $5 \mathrm{~g} \cdot \mathrm{m}^{-2}$ represents the senescence adjustment which is added to the estimates of Method 1. The decay correction involves decreases in standing dead biomass that are not justified by increase in litter. For example, if between 2 sample periods the increases in litter are higher than the decreases in standing dead biomass, the difference represents a decay adjustment and is added to the estimates of Method 1. For the rationale behind these adjustments see Sala et al. (1981).

Adjustments for increases in standing dead and litter are accomplished with the use of the same 4 steps of example 1 . Decreases in live and standing dead biomass between 2 sample periods can be treated as increases by changing the time direction
(B1-B2 rather than B2-B1, which is equivalent to calculating the Abs(B2-B1)) and adjusted by following the same 4 steps of example 1. For example, let's look at the case of forbs in the December 1974 to January 1975 interval: (a) we first check that the decrease in live biomass of $-10.5 \mathrm{~g} . \mathrm{m}^{-2}$ is in fact statistically significant (which it is at $\mathrm{p}<0.05$ ); and (b) as in step 3 of example 1 we calculate the adjustment by solving the system of equations (1) and (2) of the Appendix. In this case $\mathrm{E}(\mathrm{NPP})=\mathrm{Abs}(-10.5)=10.5$, $\operatorname{Var}(\mathrm{NPP})=$ $(12.3)^{2}+(6.4)^{2}=192.25, \mathrm{z}=-10.5 /(192.25)^{1 / 2}=-0.76, \mathrm{p}=1-$ $\mathrm{P}(\mathrm{Z}<-0.76)=0.22$. The adjusted decrease of biomass was $5.1 \mathrm{~g} \cdot \mathrm{m}^{-2}$. Danthonia montevidensis, Lolium multiflorum, Stipa neesiana also had significant decreases in live biomass for the period, which amounts to $8.2,16.6$, and $13.6 \mathrm{~g} . \mathrm{m}^{-2}$ respectively. The corresponding adjusted values are 0 (the actual adjusted value is -5.6 , thus the 0 ), 9.5 and 0 (actual value -4.5 ). For the same period, there is a significant increase in standing dead of $121.8 \mathrm{~g} \cdot \mathrm{m}^{-2}\left(49.9 \mathrm{~g} . \mathrm{m}^{-2}\right.$ adjusted) which is greater $(p<0.05)$ than the sum of the decreases (adjusted and nonadjusted) in live biomass of individual species. 
The senescence correction factor is then equal to a nonadjusted 72.9 g.m ${ }^{-2}(121.8-8.2-16.6-13.6-10.5)$ and adjusted $35.3 \mathrm{~g} \cdot \mathrm{m}^{-2}$ (49.9-9.5-5.1). The decay correction is calculated in a similar manner using decreases in standing dead and increases in litter. This procedure is repeated for every consecutive date that shows significant differences in standing dead and litter. NPP is then calculated by adding the correction factors to the NPP estimates of Method 1 (Table 2).

\section{Discussion and Conclusions}

The main methodological difference between the 2 examples shown in this paper is number of taxonomic (species) and tissue categories (live biomass, standing dead, and litter) used. We used only 1 category (total root biomass) in example 1 , while in example 2 we used 33 (live biomass of 31 species plus standing dead and litter). The differences found between nonadjusted and adjusted (for overestimation) estimates of NPP in example 2 were $394 \%$ for method 1 and $455 \%$ for method 2 , which are far higher than the one found in example $1(200 \%)$. This differences can be explained by another of Sala et al. (1988) results that showed that increasing the number of sampling components is equivalent to increasing the frequency of sampling, both of which lead to increases in NPP overestimation if values are not properly adjusted. If adjustments are performed, however, increasing the number of plant categories sampled, the frequency of sampling, or both, increases the accuracy of the NPP estimates by reducing the biomass peaks that are missed, and by accounting for senescence. We want to emphasize, however, that overestimation is not the only factor that can affect estimates of NPP based on harvest techniques. The main source of error is still the difference between the concept of NPP and the way we calculate it. In a strict sense NPP is the difference between the energy fixed by autotrophs and their respiration. All the techniques we commonly use to estimate NPP are an approximation to that value and thus, as we explained before, tend to lead to underestimation. The peculiarity of the overestimation problem, however, is that it is strictly the result of a statistical artifact related to the empirical way we estimate NPP and thus can be rigorously dealt with by the use of an appropriate statistical method. Adjustments for overestimation do not guarantee an accurate estimate of NPP but eliminate an unneeded source of error.

The general conclusions that can be made on the subject of overestimation are as follow:

1. Random errors associated with field estimates of above- or belowground biomass do not cancel each other but always result in a positive bias which may result in overestimation of NPP.

2. The overestimation in NPP increases (as a percentage) with (a) increases in the variance of biomass estimates, (b) decreases in the difference (though still statistically significant) in mean biomass between time periods, and (c) increases in the frequency of sampling and/or the number of tissue categories and taxonomic groups sampled. This overestimation can be as high as $700 \%$. We presented examples with overestimation in the $200 \%$ to $400 \%$ range for above- and belowground NPP.

3. Sala et al. (1988) developed the statistical theory for the overestimation problem and the analytical solution to deal with it. The authors have developed a computer program to implement it. The program can be run on any IBM ${ }^{\mathrm{TM}}$ compatible $\mathrm{PC}$ and is available from the authors free of charge (send a blank diskette).

4. Once adjustments for overestimation are performed, more sophisticated methods for field estimations of NPP that involve frequent sampling, separation of live and dead material, estimation of decomposition rates, and estimation of $\mathrm{C}$ translocation (Sala et al. 1981) can be safely used to obtain more accurate estimates of NPP without incurring overestimation.

5. Adjustments for overestimation in NPP are critical in range management because of the central role that estimates of plant production have in determinations such as range condition and stocking rates, the design of grazing systems, and the estimation of animal consumption.

\section{APPENDIX}

In this section we present statistical relationships between actual and field estimations of NPP developed by Sala et al (1988).

\section{Distribution function of NPP estimates}

$F_{\text {NPP }}(N P P)=q+G_{C N P P}(N P P)$ (Cumulative Distribution) where $\mathrm{G}_{\mathrm{CNPP}}(\mathrm{NPP})=(2 \pi)^{-1 / 2}(\sigma p)^{-1} \int_{0}^{\mathrm{Npp}} \mathrm{e}^{-1 / 2(\mathrm{x}-\mu) / \sigma)^{2}} \mathrm{dx}$

$\mu$ and $\sigma$ represent the mean and variance of the real difference in biomass between time 1 and time 2 (the real NPP), $q$ is the probability of measuring a decline of biomass in the time 1 time 2 period when there is actually an increase, $p=1-q$, and NPP is the estimated NPP (Figure 1c,ld).

2. Relationship between the field estimated and actual mean and variances of NPP

$$
\begin{aligned}
& \mathrm{E}(\mathrm{NPP})=\mathrm{p} \mu+\sigma(2 \pi)^{-1 / 2} \mathrm{e}^{1 / 2(\mu / \sigma)^{2}} \\
& \operatorname{Var}(\mathrm{NPP})=\mathrm{p} \mu^{2}(1-\mathrm{p})+\mathrm{p} \sigma^{2}+\mu \sigma(2 \pi)^{-1 / 2} \mathrm{e}^{-1 / 2(\mu / \sigma)^{2}}(1-2 \mathrm{p}) \\
& -\sigma^{2}(2 \pi)^{-1} \mathrm{e}^{(\mu / \sigma)^{2}}
\end{aligned}
$$

where E(NPP) and $\operatorname{Var}(\mathrm{NPP})$ are the mean and variance of the field estimates of NPP.

\section{Overestimation error}

$$
\begin{array}{r}
\mathrm{OE}=\sigma(2 \pi)^{-1 / 2} \mathrm{e}^{-1 / 2(\mu / \sigma)^{2}}-\mathrm{q} \mu \\
\text { Literature Cited }
\end{array}
$$

\section{Literature Cited}

Lauenroth, W.K., and W.C. Whitman. 1977. Dynamics of dry matter production in a mixed-grass prairie in western North Dakota. Oecologia 27:339-351

Lauenroth, W.K., H.W. Hunt, D.M. Swift, and J.S. Singh. 1986a. Estimating aboveground net primary production in grasslands: a simulation approach. Ecol. Model. 33:297-314.

Lauenroth, W.K., H.W. Hunt, D.M. Swith, and J.S. Singh. 1986 b. Response to Vogt et al. Ecology 67:580-582.

Sala, O.E., V.A. Deregibus, T. Schlichter, and H. Alippe. 1981. Productivity dynamics of a native temperate grassland in Argentina. J. Range Manage. 34:48-51.

Sala, O.E., M.E. Biondini, and W.K. Lauenroth. 1988. Bias in estimates of primary production: an analytical solution. Ecol. Model. 44:43-55.

Schneider, S.H. 1989. The greenhouse effect: science and policy. Science 243:771-781.

Singh, J.S., W.K. Lauenroth, and R.K. Steinhorst. 1975. Review and assessment of various techniques for estimating net aerial primary production in grasslands from harvest data. Bot. Rev. 41:181-232.

Singh, J.S., W.K. Lauenroth, H.W. Hunt, and D.M. Swift. 1984. Bias and random errors in estimators of net root production: a simulation approach. Ecology 65:176-1764.

Snedecor, G.W., and W.G. Cochran. 1967. Statistical Methods. Iowa State University Press, Ames.

Vogt, K.A., C.C. Grier, S.T. Gowen, D.G. Sprugel, and D.J. Vogt. 1986. Overestimation of net root production: a real or imaginary problem? Ecology 67:577-579.

Wiegert, R., and F.C. Evans. 1964. Primary production and the disappearance of dead vegetation on an old field. Ecology 45:49-63. 